Faculdade

de Ciências Econômicas UFRGS

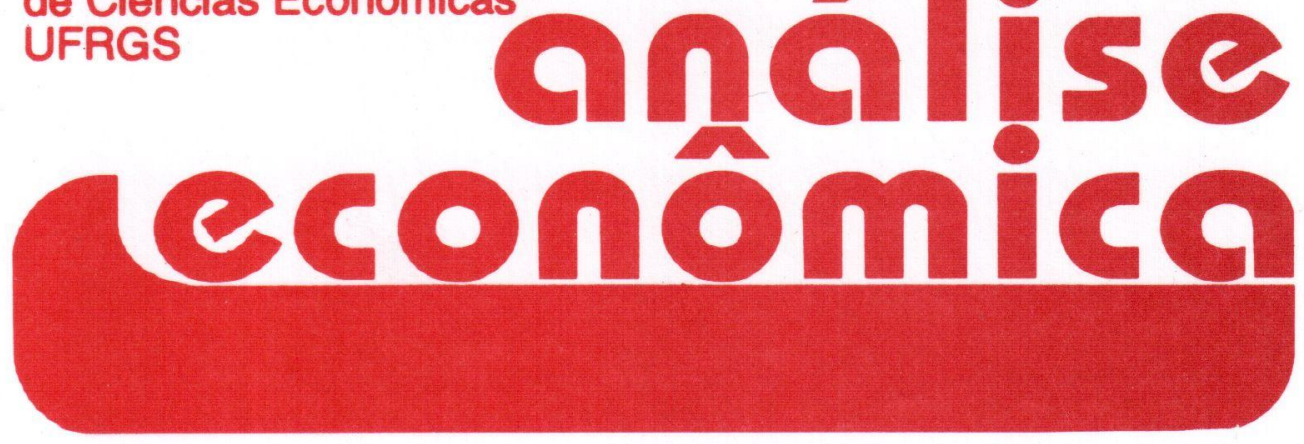

- Finance and Growth:

is Schumpeter Right?

- Philip Arestis

- Panicos Demetriades

- Repensando a

Revolução Marginalista

- Ricardo Luis C. Feijó

- O Papel dos

Rendimentos Crescentes

na Localização Econômica

- Paulo Augusto P. de Britto

- Credibilidade e Mercado Secundário da Dívida Externa Brasileira

- Paulo Calderon

- Rosa Fontes

- Fronteira de Eficiência sob Condições de Risco

- Luís A. de Araújo

- José Vicente Caixeta Filho

- A Criação de

Municípios e seu Impacto na

Qualificação do Espaço Urbano

- Maria Conceição B. Scussel

- Um Estudo Crítico das Relações entre as Poupanças Privada,

Pública e Nacional

- Martin R. Cavalcanti

- Joanílio R. Teixeira
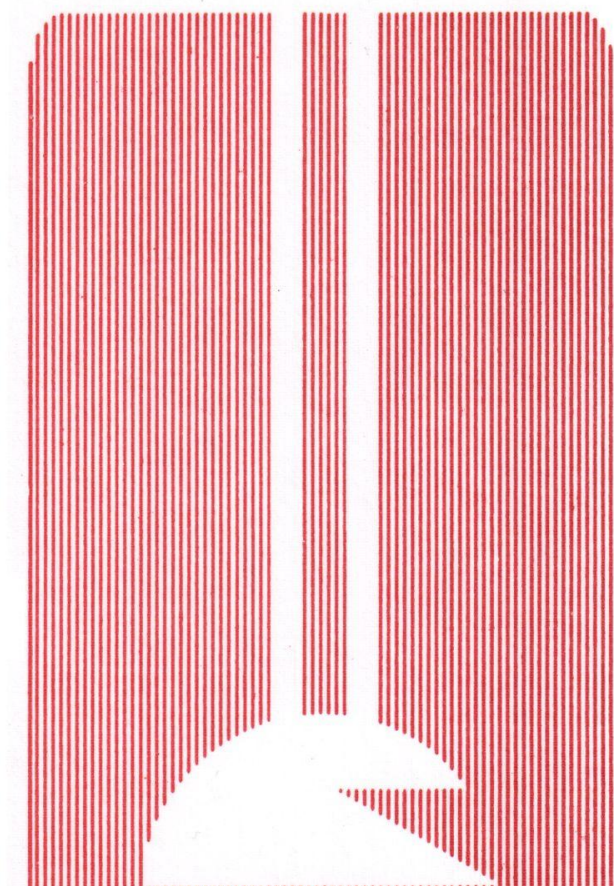

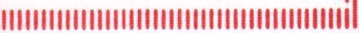

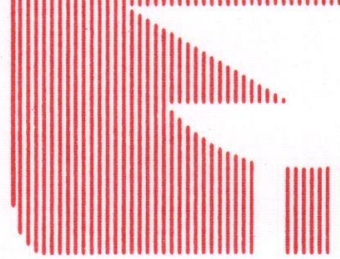

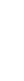


UNIVERSIDADE FEDERAL DO RIO GRANDE DO SUL

Reitora: Prof ${ }^{\mathrm{a}}$. Wrana Maria Panizzi

FACULDADE DE CIÊNCIAS ECONÔMICAS

Diretora: Prof ${ }^{\mathrm{a}}$. Otilia Beatriz Kroeff Carrion

CENTRO DE ESTUDOS E PESQUISAS ECONÔMICAS

Diretor. Prof. Fernando Ferrari Filho

DEPARTAMENTO DE CIÊNCIAS ECONÔMICAS

Chefe: Prof. Luiz Alberto Oliveira Ribeiro de Miranda

CURSO DE PÓS-GRADUAÇÃO EM ECONOMIA

Coordenador. Prof. Marcelo Savino Portugal

CURSO DE PÓS-GRADUAÇÃO EM ECONOMIA RURAL

Coordenador. Prof. Carlos Guilherme A. Mielitz Netto

CONSELHO EDITORIAL: Achyles B. Costa, Aray M. Feldens, Carlos A. Crusius, Carlos G. A. Mielitz Netto, Eduardo A. Maldonado Filho, Eduardo P. Ribeiro, Eugênio Lagemann, Fernando Ferrari Filho, Gentil Corazza, Marcelo S. Portugal, Nali J. Souza, Otília B. K. Carrion, Paulo A. Spohr, Paulo D. Waquil, Pedro C. D. Fonseca, Roberto C. Moraes, Ronald Otto Hillbrecht, Stefano Florissi, Eleutério F. S. Prado (USP), Fernando H. Barbosa (FGV/RJ), Gustavo Franco (PUC/RJ), João R. Sanson (UFSC), Joaquim P. Andrade (UnB), Juan H. Moldau (USP), Paul Davidson (Univ. of Tennessee), Werner Baer (Univ. of Illinois).

COMISSÃO EDITORIAL: Fernando Ferrari Filho, Gentil Corazza, Paulo Dabdab Waquil, Marcelo Savino Portugal, Roberto Camps Moraes.

EDITOR: Eduardo Augusto Maldonado Filho

EDITOR ADJUNTO: Gentil Corazza

SECRETARIA: Revisão de textos: Vanete Ricacheski.

FUNDADOR: Prof. Antônio Carlos Santos Rosa

Os materiais publicados na revista Análise Econômica são da exclusiva responsabilidade dos autores. É permitida a reprodução total ou parcial dos trabalhos, desde que seja citada a fonte. Aceita-se permuta com revistas congêneres. Aceitam-se, também, livros para divulgação, elaboração de resenhas e recensões. Toda correspondência, material para publicação (vide normas na terceira capa), assinaturas e permutas devem ser dirigidos ao seguinte destinatário:

PROF. EDUARDO AUGUSTO MALDONADO FILHO

Revista Análise Econômica - Av. João Pessoa, 52 CEP 90040-000 PORTO ALEGRE - RS, BRASIL

Telefones: (051) 316-3324 e 316-3440 - Fax: (051) 316-3990 rae@vortex.ufrgs.br 


\title{
CREDIBILIDADE E MERCADO \\ SECUNDÁRIO DA DÍVIDA EXTERNA BRASILEIRA
}

\author{
Paulo Calderon \\ Rosa Fontes **
}

\begin{abstract}
RESUMO
Esse artigo utiliza o preço do titulo IDU da divida externa brasileira no mercado secundário como possível "proxy" de credibilidade. Após fazer uma retrospectiva do crescimento da divida externa brasileira nos últimos 30 anos, correlaciona-se o preço do titulo IDU com a inflação esperada, no período de janeiro de 1986 a marco de 1997, verificando-se, conforme previsto, uma associação negativa entre essas variáveis. Observando-se o comportamento do preço da divida externa brasileira no mercado secundário frente aos planos de estabilização das décadas de 80 e 90 , verifica-se que o Plano Real foi, em comparação com os anteriores, relativamente mais crivel. Por ultimo, testa-se e confirma-se as hipóteses de correlação negativa entre taxas de juros interna e internacional com o titulo da divida externa IDU e correlação positiva entre reservas internacionais e titulo da divida externa IDU.
\end{abstract}

Cód AEA: 463

Palavras-Chave: credibilidade, dívida externa, planos econômicos

ABSTRACT

This paper uses the IDU Brazilian external debt bond price as a credibility proxy. It first describes the Brazilian external debt growth over the past 30 years. Then it correlates the IDU Brazilian bond price with expected inflation, from January 1986 to March 1997, finding a negative association between then. Observing the IDU Brazilian bond price behavior during several stabilization plans in the $80^{\prime} \mathrm{s}$ and $90^{\prime} \mathrm{s}$, it is shown that the Real Plan was relatively more credible in comparison to others. Lastly it finds a negative correlation between the IDU bond price and internal and external interest rates and a positive correlation between the IDU bond price and Brazilian international reserves.

AEA Cód: 463

Key words: Credibility, External Debt, Economic Plans

*Economista pela Universidade Federal de Viçosa e Mestrando da ESALQ-USP,

Piracicaba.

${ }^{\star \star P}$ rofessora do Departamento de Economia da Universidade Federal de Viçosa, Minas Gerais.

\begin{tabular}{|l|l|l|l|l|}
\hline ANÁLISE ECONÔMICA & ANO 16 & N.30 & SETEMBRO/98 & p. 69-90 \\
\hline
\end{tabular}




\section{1 - INTRODUÇÃO}

A credibilidade que os agentes privados associam às políticas econômicas governamentais é uma variável de suma importância na macroeconomia moderna. Uma política econômica consistente e crível exerce uma influência positiva sobre as expectativas dos agentes econômicos, diminuindo, consequentemente, os custos macroeconômicos da política implantada.

Apesar da modelagem teórica sobre credibilidade ter se desenvolvido substancialmente nos últimos anos, os trabalhos empíricos não acompanharam os desenvolvimentos teóricos ${ }^{1}$. Persson (1988) ressalta que análises empíricas sobre credibilidade ainda não foram devidamente exploradas, devendo ser essa uma importante tarefa para agendas futuras.

O presente trabalho pretende aprofundar-se nessa linha de pesquisa, concentrando-se no problema do endividamento externo que assolou o Brasil nas últimas décadas e enfatizando os preços referenciais dos títulos da dívida externa como possíveis indicadores empíricos de credibilidade. Em outras palavras, a valorização ou desvalorização dos papéis brasileiros no exterior, que expressa o chamado risco Brasil, é aqui usada como proxy de credibilidade.

A parte 1 faz uma retrospectiva do crescimento da dívida externa do Brasil nos últimos 30 anos. A parte 2 apresenta uma análise de correlação entre a sugerida proxy de credibilidade - preço da dívida externa no mercado secundário - e inflação esperada, testando-se a hipótese de que existe uma correlação negativa entre elas, no período de janeiro de 1986 a março de 1997. Verifica-se posteriormente o comportamento do preço da dívida externa no mercado secundário frente aos diferentes planos de estabilização desse período. A parte 3 analisa a correlação existente entre o preço da dívida externa no mercado secundário em relação à taxa de juros interna, à taxa de juros internacional e às reservas internacionais. A parte 4 apresenta as principais conclusões.

\section{2 - RETROSPECTIVA DA DÍVIDA EXTERNA BRASILEIRA}

O período entre 1968-1973 foi marcado por um vigoroso crescimento do produto brasileiro, que atingiu uma média de $11,4 \%$ ao ano, o qual ficou conhecido como milagre económico. Foi neste período que houve o primeiro grande surto da dívida externa brasileira, que passou de um montante de 3,8 bilhões de dólares em fins de 1968 para 12,6 bilhões de dólares em fins de 1973.

\footnotetext{
${ }^{1}$ Ver Arbex et al (1997) para uma resenha detalhada dos desenvolvimentos teóricos e empíricos sobre credibilidade.
} 
A captação de depósitos para o Euromercado, mercado de dólares na Europa, tornou-se uma unanimidade no tocante às alternativas de aplicações financeiras após o primeiro choque do petróleo em 1973, quando paises como Arábia Saudita, Kuwait e Líbia se viram subitamente com grandes excedentes em dólar para investir. Conforme enfatiza Moffit (1984), o Euromercado, de origens modestas e inseguras, logo se tornou o quartelgeneral do Sistema Financeiro Mundial, reunindo hoje a impressionante cifra de mais de US $\$ 2$ trilhões.

Para Lopes (1982), o novo sistema era não só precário, por não possuir regras de convivência coletiva que o dotassem, em contrapartida, de emprestadores de última instância, mas também de extrema fragilidade financeira. Isto porque ele supria uma necessidade de longo prazo dos paises do Terceiro Mundo, com base em recursos de curto prazo, depositados nos bancos privados, pelos eventuais detentores de superávites em conta corrente.

O Euromercado gerou, em síntese, uma extraordinária disponibilidade de créditos a prazos cada vez mais longos e spreads cada vez menores, no decorrer da década de 70 . Neste sentido, a economia brasileira, ao elevar seu nível de endividamento externo, nada mais fez do que acompanhar um movimento geral que envolveu diversas economias em desenvolvimento, num momento em que o Euromercado buscava novos clientes fora dos EUA e Europa. Para Cruz (1984), a economia brasileira foi "capturada", juntamente com outras economias, num movimento geral do capital financeiro internacional em busca de oportunidade de valorização.

As autoridades governamentais adotaram, a partir de meados de 1976, uma política fortemente indutora de tomada de recursos externos. Por um lado, essa busca de recursos se deu através de estímulo à captação privada, de resultados não tão expressivos, mas que pôde se concretizar via liberação das taxas internas de juros, visando garantir um diferencial do custo do dinheiro a favor do crédito externo. Além disso, foi instituído, em meados de 1977, um mecanismo de proteção contra perdas de capital decorrentes de eventuais modificações na política cambial. Simultaneamente, as empresas estatais foram induzidas, via crescentes restrições à mobilização de recursos internos, às tomadas maciças de empréstimos junto aos bancos internacionais. Em função dessa política, os recursos externos passaram a ter peso crescente na estrutura de financiamento dos grandes projetos do setor público, o que marcou, sem dúvida, o primeiro processo de estatização significativa da dívida externa brasileira.

Os anos 80 marcaram o início de um conturbado período de renegociação da divida externa associado à instabilidade econômica dos paises endividados. 
A vulnerabilidade da economia brasileira, no final da década de 70 , era grande, com o serviço da dívida externa dependendo da taxa de juros internacional. À medida que as economias desenvolvidas entraram num processo de forte recessão, essa fragilidade aumentou ainda mais.

É importante, contudo, que seja entendido o tipo de financiamento que os países faziam nessa época. Tanto o Brasil quanto os outros países que se endividaram na década de 70 faziam financiamentos do tipo especulativo, na definição de Minsky, citado por Resende (1982). Para contas externas, num horizonte de curto ou mesmo de médio prazo, o fluxo de receitas advindas de exportações de bens e serviços era inferior ao fluxo de pagamento de importações e serviços da dívida, característica marcante desse tipo de financiamento, conforme ressalta Mollo (1988). Certamente os países se endividavam tendo como parâmetro para sua capacidade de pagamento uma dada taxa de juros, que seguia uma tendência histórica.

Os preços dos empréstimos integrados eram fixados a partir da taxa de juros corrente, conhecida como LIBOR (taxa de oferta interbancária em Londres), adicionada de uma margem, o spread, que é inversamente proporcional à credibilidade atribuída ao tomador do empréstimo, conforme enfatiza Moffit (1984).

Parte importante da origem da crise da dívida, na década de 80 , cabe à acentuada queda da economia mundial verificada entre 1979-81. Os EUA, sob a pressão de um colapso do dólar, modificaram radicalmente sua política econômica, anteriormente expansionista e com taxas crescentes de inflação. De acordo com Dornbusch (1988), o orçamento americano de pleno emprego foi cortado em $1,5 \%$ do PNB. As taxas nominais de juros subiram de $9 \%$ em 1978 para $17 \%$ em 1981 e, consequentemente, a LIBOR subiu para mais de $14 \%$ entre 1980-82.

O Brasil não só foi prejudicado com o aumento das taxas de juros externas, como também lesado duplamente no âmbito das relações comerciais. Primeiro, porque os preços das commodities caíram no mercado internacional em $13,3 \%$ a.a. no período 1979-81, enquanto que o preço dos manufaturados caíram apenas $2,4 \%$ a.a.; e segundo, porque o preço do petróleo, elemento em grande parte importado e indispensável à estrutura produtiva brasileira, aumentou significativamente.

Atribui-se, todavia, que a crise da dívida no mundo teve início em agosto de 1982, quando o México chocou a comunidade financeira internacional anunciando que não podia honrar seus compromissos da dívida de acordo com seu cronograma.

Camargo (1982) vê uma causa mais estrutural na origem da crise da dívida, com uma enorme dependência brasileira em relação ao petróleo importado. Primeiro, porque o setor industrial brasileiro instalou uma tecnologia cuja fonte principal de energia era o óleo combustível. Segundo, 
porque houve um estímulo à substituição do transporte ferroviário pelo rodoviário para passageiros e para carga, com um aumento nas estradas asfaltadas para escoar a produção. Finalmente, porque pouco foi realizado no sentido de melhorar os transportes coletivos de massa nas grandes cidades, estimulando-se os meios de transportes individuais.

Foi também nesta década que o setor privado, utilizando-se de mecanismos criados em meados da década de 70 , transferiu para as autoridades monetárias a responsabilidade pela sua parcela da dívida externa, realizando depósitos no Banco Central do Brasil (Bacen) que eram registrados em moeda estrangeira. Bacha (1990) ressalta que até 1983 o Governo Federal e o Bacen conseguiram honrar o pagamento dos compromissos externos, complementando a entrada de recursos estrangeiros com a redução das reservas internacionais. De acordo com Cruz (1995), o que confere especificidade a essa segunda etapa de estatização da dívida é a transformação do Banco Central em depositário crescente de passivos denominados em moeda estrangeira, seja através da transferência maciça de dívidas velhas, contratadas originalmente pelo setor privado, ou através de depósitos de projetos oriundos da sistemática de negociação instituída em 1982, após a interrupção das linhas voluntárias de crédito. A dívida de responsabilidade do setor público rapidamente ultrapassou a casa dos $80 \%$ do total da dívida externa.

Para agravar a situação, a partir de 1982 houve uma queda vertical nos investimentos externos diretos no Brasil, simultaneamente a uma elevação das remessas de lucros e dividendos. O governo lança então, no ano de 1984, um programa de conversão da dívida externa em investimentos. Desta forma, como ressalta Serra (1988), poder-se-ia proporcionar, via conversão, um importante alívio do endividamento externo do país, mediante transformações da dívida externa em capital de risco pertencente a residentes no exterior. Paralelamente, estar-se-ia estimulando o investimento no mercado externo, o saneamento financeiro e a capitalização das empresas. Contudo o que poderia acontecer é que, em vez de pagamento de juros, haveria remessa de lucros, ou seja, em vez de amortização da dívida, haveria repatriação de capital.

Com o programa de conversão, o investidor poderia, em tese, comprar de um banco, no mercado secundário, títulos da dívida externa brasileira, por um preço menor do que o fixado. Mas quando estes ingressassem no Brasil, na forma de investimento, eles entrariam com seu valor de face subscrito. Para o comprador ou para o próprio banco, aventava-se a possibilidade do ganho ao converter o crédito em investimento. Apesar de, a partir de 1985, serem convertidos mais de meio bilhão de dólares, dada a dimensão da dívida e dos juros, esta não chegou a ser uma alternativa que amenizasse o problema do endividamento externo brasileiro. 
Cohen (1988) enfatiza que o ajustamento brasileiro foi muito pouco significativo na década de 80 . O desajuste interno foi provocado pelo ajuste externo parcial, com a dívida interna tomando o lugar da dívida externa. $O$ governo, em síntese, emitia moeda para comprar dólares dos exportadores e honrar o serviço de sua dívida externa.

Sob estas circunstâncias, o autor defende um pagamento mais ameno da dívida externa, combinado à postura de uma política fiscal mais dura, para obtenção de resultados mais satisfatórios tanto para o devedor quanto para os credores.

As tentativas de renegociação da dívida na década de 80 diminuíram. Ademais, havia uma percepção generalizada de que esta era uma crise de liquidez de caráter temporário e que a solução do problema, embora não fosse de curto prazo, estaria garantida a médio e longo prazo, mediante a adoção de políticas macroeconômicas adequadas.

O primeiro sinal de reconhecimento por parte da comunidade financeira internacional, mais especificamente do governo americano, de que o problema da dívida não teria uma solução automática de mercado, se deu em outubro de 1985, com o anúncio do Plano Baker. Até então, esta foi a manifestação mais notória da mudança de atitude dos credores, que foi formulada pelo Secretário do Tesouro dos EUA. De acordo com Ferrer (1987), a referida iniciativa reconhecia explicitamente a necessidade de avaliar o processo de ajuste e de vinculá-lo ao desenvolvimento econômico e, ainda, considerava que, no futuro, seria inevitável refinanciar maiores proporções dos juros devidos. A partir desses fatos, os novos créditos do sistema bancário público e privado foram condicionados ao cumprimento de políticas econômicas que abrissem os mercados internos dos devedores, liberalizassem o tratamento do investimento estrangeiro e reduzissem a intervenção estatal nas respectivas economias. Contudo o Plano Baker encontrou pouca aplicabilidade, dentre outras razões porque o crédito privado internacional prometido não foi oferecido pelos bancos credores. Em 1986, no lugar de uma prevista expansão das linhas de crédito para os grandes devedores, o comportamento dos bancos privados e das agências governamentais, como Fundo Monetário Internacional (FMI), acabou resultando, para a economia brasileira, num fluxo negativo de recursos externos líquidos.

Carmichael (1989) ressalta que, em termos pragmáticos, acordos gerais que envolvessem uma solução efetiva para o problema da dívida deveriam conter as seguintes características:

(i) estimular o investimento e, através deste, impulsionar o crescimento econômico e o desenvolvimento;

(ii) reduzir a proteção financeira dos países industrializados e; 
(iii) implementar reformas políticas domésticas nos países em desenvolvimento nos níveis macro e microeconômico. Em nível macroeconômico seriam especialmente restrições fiscais e controle da taxa de câmbio, enquanto que em nível microeconômico seriam reformas referentes à eliminação de distorções internas e liberalização de mercados.

Os acordos assinados nos primeiros anos da década de 80 previam o equilíbrio das contas externas brasileiras, através da geração de grandes superávites comerciais. Porém, como disse Horta (1992), isso não foi possível, dada uma inversão no sinal da balança comercial decorrente do superaquecimento da economia de 1986 e devido também ao atraso cambial provocado pelo Plano Cruzado, que acabou gerando uma drástica redução das reservas internacionais.

O nivel crítico alcançado por tal conjuntura levou o governo brasileiro a decretar a suspensão do pagamento dos juros da dívida de médio e longo prazo, junto aos bancos comerciais estrangeiros, em fevereiro de 1987.

Com o fracasso do Plano Baker, viu-se que o pagamento da dívida, mesmo com empréstimos adicionais de curto e médio prazo, era impossivel para a maioria das nações devedoras. Isso gerou um descontentamento entre os países devedores, com alguns bons pagadores começando a atrasar seus pagamentos. Com a diminuição das renegociações mediadas pelos comitês bancários, o mercado secundário se expandiu drasticamente, sinalizando a deterioração dos esquemas convencionais de cobrança da dívida externa.

Cohen (1990) ressalta que uma divida externa excessiva gera ineficiências, sendo uma delas a existência de preços de títulos da dívida com descontos criados pelo mercado secundário. Quando um título é vendido por um preço menor do que seu preço de face, suponha $50 \%$ de desconto, referente ao risco do país não honrar seu compromisso, o ganho adicional, quando ele mesmo faz a aquisição ou o pagamento do título, não é revertido para o país devedor. Esta é uma causa de ineficiência provocada pelo desconto do título quando negociado no mercado secundário.

Vários esquemas foram propostos, e alguns até mesmo implementados parcialmente, no sentido de permitir que o devedor recomprasse sua dívida no mercado secundário, utilizando suas reservas internacionais. Porém os empréstimos originais proíbem a compra do título pelo devedor.

Segundo Eaton (1993), a compra dos títulos pelo devedor vem tomando várias formas: (i) uma simples compra utilizando recursos próprios; (ii) uma compra normal utilizando recursos doados; e (iii) acordos de permuta. Sob esta última e especial forma, o governo troca a dívida externa por moeda doméstica a um determinado preço, porém o uso dessa moeda é 
limitado à utilização em investimento estrangeiro direto no país devedor ou em proteção ambiental.

Esta terceira prática tem gerado muita polêmica, segundo Eaton, porque, em determinadas circunstâncias, pode haver um incentivo, por parte do devedor, a repudiar o serviço da dívida, o que provocaria um desconto maior no mercado secundário e permitiria, subseqüentemente, que o devedor se apropriasse de ganhos espetaculares na aquisição de seus papéis.

Diante de um cenário crescentemente adverso aos reescalonamentos convencionais, era necessário e urgente estabelecer uma ponte entre a rigidez dos comitês e as práticas do mercado secundário. De acordo com Filho (1994), o governo americano, com o intuito de amenizar e, se possível, resolver o problema, lançou, em março de 1989, uma nova proposta para a dívida externa, formulada pelo então atual Secretário do Tesouro dos EUA, Nicholas Brady. Pela primeira vez o governo americano reconhecia a necessidade de reduzir a dívida externa dos países superendividados. Porém, conforme enfatiza Sachs e Larrain (1995), o Plano Brady não considerava as especificidades e detalhes a serem negociados com cada nação e seu credor externo, mas delineava o mecanismo geral para atingir a redução da dívida. As nações tinham que negociar com os bancos credores para reduzir seu passivo, por meio de redução da taxa de juros ou redução do principal.

Sob o mesmo esquema, as nações deveriam apresentar aos bancos várias opções para redução da dívida, e os bancos fariam a opção desejada. Ao mesmo tempo, alguns bancos poderiam optar por fornecer novos créditos à nação devedora, em vez de aceitar a redução da dívida.

A renegociação nos moldes do Plano Brady não era de fácil elaboração e levava um determinado período de tempo. O Brasil suspendeu novamente a remessa de determinados pagamentos de juros para o exterior, em julho de 1989.

A verdade é que, durante toda a década de oitenta, o Brasil enfrentou notórias dificuldades no pagamento do serviço de sua divida externa, provocando um quadro de instabilidade macroeconômica, onde o país não conseguiu gerar uma capacidade de pagamento de suas obrigações externas na magnitude requerida pelos acordos que assinou com seus credores. Posto de outra forma, estes acordos superestimavam a real capacidade do país de gerar interna e externamente os recursos necessários ao cumprimento das obrigações resultantes.

Foi na década de 90 que se efetivou a renegociação da dívida externa proposta pelo Plano Brady. A renegociação brasileira foi realizada sob regime de moratória parcial. Nos termos da Resolução $n^{0} 1.838$ do Conselho Monetário Nacional, citado por Filho (1994), foram remetidos 
apenas $30 \%$ dos juros devidos sobre a dívida durante a fase inicial de negociação. O Brasil obteve um acordo preliminar com os bancos comerciais em 9 de julho de 1992. As trocas foram realizadas em 1994. De acordo com Cerqueira (1995), o elemento essencial de acordos desse tipo é a renovação da divida, mediante sua troca por bônus de emissão do governo do país devedor, cujos termos envolvem abatimento do encargo da divida, seja sob a forma de redução de seu principal, seja por alívio da carga de juros.

Para estimular a adesão dos credores, os bônus contam com a garantia integral ou parcial de pagamento de principal e/ou de juros. A garantia de principal é dada, na maioria das vezes, sob a forma de caução de títulos emitidos pelo Tesouro americano, cujo montante de resgate, quando de seu vencimento, pode ser utilizado no pagamento de principal dos bônus por eles garantidos. A garantia de juros, por sua vez, toma a forma de um depósito efetuado em conta especial, em montante que é reinvestido de forma previamente acordada, e computado como parte integrante das reservas internacionais do País. Na aquisição das garantias, o país devedor conta normalmente com financiamento oriundo dos organismos multilaterais - Fundo Monetário Internacional e Banco Interamericano de Desenvolvimento.

O acordo firmado entre o Brasil e seus credores privados externos contemplou as obrigações de responsabilidade do setor público brasileiro, onde se efetivou, num primeiro instante, a troca da dívida por uma combinação de seis bônus de emissão da República, com as suas características listadas no Quadro 1 a seguir: 
Quadro1 - Características dos Bônus de Emissão da Dívida Externa Brasileira

\begin{tabular}{|c|c|c|c|c|}
\hline Bônus & Prazo & Taxa de juros & Garantia & Desconto \\
\hline $\begin{array}{l}\text { Bônus de } \\
\text { Desconto } \\
\text { (Discount } \\
\text { Bond) }\end{array}$ & $\begin{array}{l}30 \text { anos, com } \\
\text { amortização } \\
\text { única ao final } \\
\text { do } 30^{\circ} \text { ano }\end{array}$ & $\begin{array}{l}\text { L.IBOR de } 6 \text { meses mais } \\
13 \text { a } 16 \% \text { a.a }\end{array}$ & $\begin{array}{l}100 \% \text { do montante do } \\
\text { principal e } 12 \text { meses de } \\
\text { pagto de juros, sob o } \\
\text { sistema de rolagem }\end{array}$ & \begin{tabular}{|l|} 
desconto \\
de $35 \%$ \\
sobre seu \\
valor de \\
face \\
\end{tabular} \\
\hline $\begin{array}{lr}\text { Bônus } & \text { ao } \\
\text { Par } & \text { (Par } \\
\text { Bond) } & \end{array}$ & $\begin{array}{l}30 \text { anos, com } \\
\text { amortização } \\
\text { única ao final } \\
\text { do } 30^{\circ} \text { ano }\end{array}$ & $\begin{array}{l}4 \% \text { no } 1^{\circ} \text { ano, } 4,25 \% \text { no } \\
2^{\circ} \text { ano, } 5 \% \text { no } 3^{\circ} \text { ano, } \\
5,25 \% \text { no } 4^{\circ} \text { ano, } 5,5 \% \\
\text { no } 5^{\circ} \text { ano, } 5,75 \% \text { no } 6^{\circ} \\
\text { ano e } 6,0 \% \text { ao ano do } 7^{\circ} \\
\text { ao } 30^{\circ} \text { anos } \\
\end{array}$ & $\begin{array}{l}100 \% \text { do montante do } \\
\text { principal e } 12 \text { meses de } \\
\text { pagto de juros, sob o } \\
\text { sistema de rolagem }\end{array}$ & - \\
\hline $\begin{array}{l}\text { Bônus de } \\
\text { Redução } \\
\text { Temporária } \\
\text { de Juros } \\
\text { (Front-Loaded } \\
\text { lnterest } \\
\text { Reduction } \\
\text { Bond - FLIRB) }\end{array}$ & $\begin{array}{|lr|}15 & \text { anos, } \\
\text { incluindo } & 9 \\
\text { anos } & \text { de } \\
\text { carência, } & e \\
\text { amortizações } \\
\text { semestrais } \\
\text { iguais }\end{array}$ & $\begin{array}{l}4 \% \text { no } 1^{\circ} \text { e } 2^{\circ} \text { ano, } \\
4,5 \% \text { no } 3^{\circ} \text { e } 4^{\circ} \text { ano, e } \\
5 \% \text { no } 5^{\circ} \text { e } 6^{\circ} \text { ano, } \\
\text { LIBOR de seis meses } \\
\text { mais } 13 \text { a } 16 \% \text { a.a. a } \\
\text { partir do } 7^{\circ} \text { ano }\end{array}$ & $\begin{array}{l}\text { o instrumento tem } \\
\text { garantia de } 12 \text { meses de } \\
\text { juros, sob o sistema de } \\
\text { rolagem, ate o } 6^{0} \text { ano, } \\
\text { inclusive. Após o } \\
\text { montante de garantia } \\
\text { retorna ao Brasil, e não } \\
\text { conta com garantia de } \\
\text { principal }\end{array}$ & - \\
\hline $\begin{array}{c}\text { Bônus de } \\
\text { Capitalização } \\
\text { (C-BOND) }\end{array}$ & $\left|\begin{array}{lr}20 & \text { anos, } \\
\text { incluindo } & 10 \\
\text { anos } & \text { de } \\
\text { carência } & \end{array}\right|$ & \begin{tabular}{|lr}
$4 \%$ no $1^{\circ}$ e $2^{\circ}$ ano, $4,5 \%$ \\
no $3^{\circ}$ e $4 \%$ ano, e $5 \%$ no \\
$5^{\circ}$ e $6^{\circ}$ ano, $8 \%$ a.a. a \\
partir do $7^{\circ}$ ano. \\
Capitalizaçāo \\
diferença entre o valor \\
pago com base nas \\
taxas indicadas para os \\
anos 1 a 6 e a $8 \%$. \\
\end{tabular} & 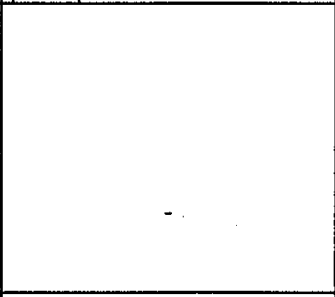 & - \\
\hline $\begin{array}{l}\text { Bônus de } \\
\text { Conversão } \\
\text { de Divida } \\
\text { (Debt } \\
\text { Conversion } \\
\text { Bond) }\end{array}$ & $\begin{array}{|lr|}18 & \text { anos, } \\
\text { incluindo } & 10 \\
\text { anos } & \text { de } \\
\text { carência } & \end{array}$ & $\begin{array}{l}\text { LIBOR de } 6 \text { meses mais } \\
7 \text { a } 8 \% \text { ao ano }\end{array}$ & $v$ & - \\
\hline $\begin{array}{l}\text { Bônus de } \\
\text { Dinheiro } \\
\text { Novo (New } \\
\text { Money Bond) } \\
\end{array}$ & $\begin{array}{|lr|}15 & \text { anos, } \\
\text { incluindo } & 7 \\
\text { anos } & \text { de } \\
\text { carência } & \\
\end{array}$ & $\begin{array}{l}\text { LIBOR de } 6 \text { meses } \\
\text { acrescida de } 7 \text { a } 8 \% \text { ao } \\
\text { ano }\end{array}$ & - & - \\
\hline
\end{tabular}

Fonte: Cerqueira (1995).

O Debt Conversion Bond, acoplado ao New Money Bond, foi o instrumento de opção dos credores que decidiram emprestar dinheiro novo ao País. Para cada 5,5 dólares de dívida antiga transformada em Debt Conversion Bond, o credor externo obrigou-se a emprestar um dólar de dinheiro novo ao Brasil, mediante a aquisição de New Money Bond.

Uma novidade no acordo firmado foi que a União passou a ser a devedora de todos os novos instrumentos emitidos em troca da dívida 
antiga. O Banco Central do Brasil deixou de figurar como responsável das obrigações externas, ao contrário das reestruturações anteriores, em que a operação baseava-se na figura de um depósito junto ao Banco Central, sendo este, formalmente, o responsável principal das obrigações externas.

Os bônus de permuta foram confeccionados pela Casa da Moeda do Brasil, sob a forma global, podendo, a critério dos seus titulares, serem trocados por bônus definitivos, denominados em US $\$ 250.000,00$.

Os bônus decorrentes da troca da dívida não conciliada foram emitidos em nome do agente de custódia e, à medida que a conciliação vem sendo processada, estão sendo feitas as transferências de titularidade - do agente para o credor detentor do crédito.

De acordo com Bacen (1994), a conclusão do acordo resultou na redução imediata de US $\$ 3,9$ bilhões de um total de US $\$ 46,7$ bilhões de divida negociada, com a emissão dos bônus de desconto. Ocorreu também a redução adicional no serviço da dívida de, aproximadamente, US\$ 4 bilhões, em valor presente, ao longo de 30 anos de pagamento. A parcela de US $\$ 42,7$ bilhões da dívida renegociada com os bancos ficou distribuída entre os seguintes instrumentos: Bônus ao Par (US\$10 bilhões), Bônus de Desconto (US $\$ 11,2$ bilhões, com desconto de $35 \%$, ou seja, de US $\$ 3,9$ bilhões), Bônus de Redução Temporária de Juros (US $\$ 1,7$ bilhões), Bônus de Conversão (US $\$ 8,5$ bilhões), Bônus de Dinheiro Novo (US\$ 1,9 bilhões), Bônus de Capitalização (US \$ 7,4 bilhões) e Bônus de Juros Atrasados (US\$ 5,4 bilhões).

Existem ainda na carteira dos investidores privados externos os IDUs (Interest Due Unpaid), juros devidos e não pagos, negociados no mercado secundário desde a década de 80 . São exatamente estes títulos que vão permitir um estudo um pouco mais abrangente, em termos de período de tempo, da credibilidade das políticas macroeconômicas adotadas nas últimas décadas.

\section{3 - CORRELAÇÃO ENTRE PREÇO DA DÍVIDA EXTERNA E INFLAÇÃO ESPERADA}

Os títulos da dívida pública externa antiga (IDUs) possuem o valor de face na ordem de US $\$ 100,00$; todavia o setor privado, muitas vezes, paga por estes títulos um preço diferente, influenciado pelas expectativas do mercado frente às políticas macroeconômicas do governo. Essa seção utiliza os preços referenciais para os títulos da dívida externa brasileira como proxy empírica de credibilidade. Em seguida, faz-se uma análise de correlação entre a proxy de credibilidade - preço da dívida externa (IDU) - e inflação esperada, testando-se a hipótese de que existe uma correlação negativa entre elas, no período de janeiro de 1986 a março de 1997 : 


$$
\tau=\operatorname{corr}\left(\mathrm{c} ; \pi^{e}\right)
$$

onde: $\tau=$ coeficiente de correlação; $c=$ Proxy de Credibilidade; $\pi^{e}=$ inflação esperada.

Espera-se, assim, poder derivar algumas inferências a respeito do comportamento do preço da dívida externa brasileira como potencial sinalizador da credibilidade associada pelo setor privado às políticas de estabilização praticadas no país no período em questão. Isso permitirá a indicação do nível de credibilidade associado a cada plano implementado no período em análise.

Os dados necessários para as análises, procedidas nesta sessão, são de fontes variadas sendo que os preços da dívida externa brasileira, mensais, para o período jan/86 - mar/97, referentes aos IDUs, foram coletados nos boletins da Macrométrica. Os dados referentes à inflação, utilizados na estimação de $\pi^{\mathrm{e}}$, foram coletados na Revista Conjuntura Econômica da Fundação Getúlio Vargas, e o indicador é o Índice Geral de Preços de Mercado (IGP-M).

A série de inflação esperada $\left(\pi^{e}\right)$ é construída com base na hipótese de expectativas adaptativas e utilizando-se a metodologia Box e Jenkins. $O$ modelo mais representativo da série inflação para o período jan/86 - mar/97 foi um ARMA $(1,2)$, transcrito na equação a seguir:

$$
\pi^{\mathrm{e}}{ }_{\mathrm{t}}=\underset{(9,877855)}{0,765692 \pi_{\mathrm{i}-1}+\underset{(1,931145)}{0,209358 \varepsilon_{\mathrm{t}-1}+0,189824 \varepsilon_{\mathrm{t}-2}} \quad(1,858845)} \quad \mathrm{R}^{2}=75,13 \%
$$

$\mathrm{O}$ valor do $\mathrm{t}$ calculado, expresso dentro dos parênteses, para cada parâmetro da equação (4), rejeita a hipótese de que os coeficientes de $\pi_{1-1}$, $\varepsilon_{\mathrm{t}-1}$ e $\varepsilon_{\mathrm{t}-2}$ são iguais a zero aos níveis de significância $1 \%, 10 \%$ e $10 \%$, respectivamente. $O$ valor do $F(130,8980)$ rejeita a hipótese de que os coeficientes da regressão são simultaneamente iguais a zero a $1 \%$ de significância. As raízes foram devidamente invertidas, o que comprova a estacionariedade da série e a possível extrapolação de seu valor futuro baseando-se em observações passadas. Uma outra ferramenta usada para a seleção do número de variáveis explicativas foi o critério Akaike de informação, tendo a equação (2) apresentado o menor valor .

A Figura 1 ilustra que a inflação esperada $\pi^{e}$, estimada para o período jan/86 - mar/97, tem comportamento bastante similar à inflação efetiva desse período. 
Figura 1 - Inflação Efetiva e Inflação Esperada Brasileira, jan/86 - mar/97

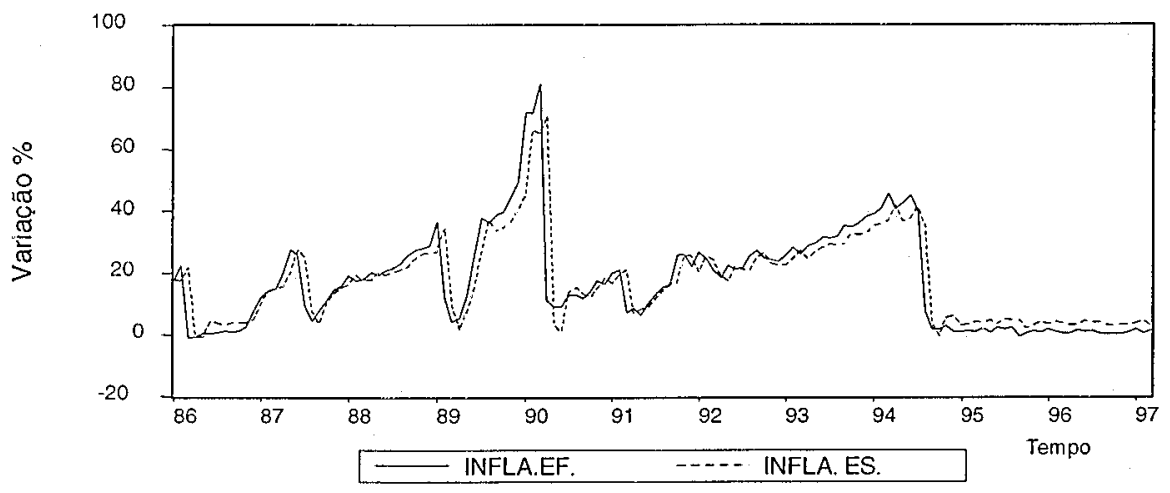

Posteriormente, realizou-se a análise de correlação entre a proxy de credibilidade - preço do IDU - e inflação esperada. A Tabela 1 fornece o resultado do coeficiente de correlação $\rho$. O valor do coeficiente encontrado $(-0,392902)$ confirma a hipótese de que há uma associação negativa entre inflação esperada e a proxy de credibilidade, sendo o t calculado

Tabela 1 - Matriz de Correlação entre Preço do IDU e Inflação Esperada $\pi^{e}$, jan/86 - mar/97.

\begin{tabular}{|c|c|c|}
\hline & IDU & $\pi^{\mathrm{e}}$ \\
\hline IDU & 1,000000 & $-0,392902$ \\
$\pi^{\mathrm{e}}$ & $-0,392902$ & 1,000000 \\
\hline
\end{tabular}

significativo a $1 \%$ de significância. A Figura 2 ilustra o comportamento das variáveis $\pi^{\mathrm{e}}$ e o preço do IDU para o período em questão.

Figura 2- Comportamento da Inflação Esperada e o IDU, jan/86 - mar/97

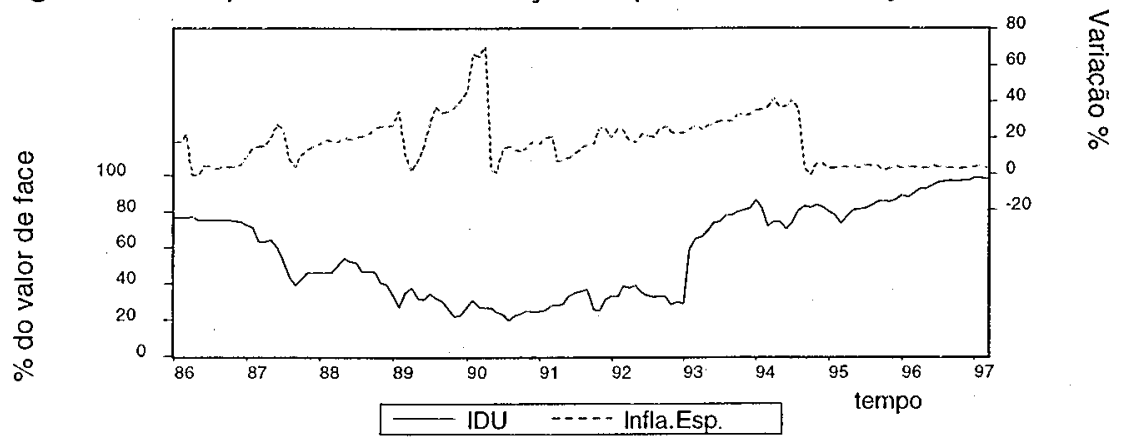


Graficamente pode-se observar, portanto, o claro comportamento antagônico das variáveis $\pi^{e}$ e a proxy de credibilidade. Em períodos de inflação elevada, o preço do IDU cai drasticamente no mercado secundário, sinalizando, assim, as expectativas dos agentes econômicos quanto ao futuro da economia.

Apresenta-se a seguir um gráfico com o comportamento do preço do IDU confrontado com os planos de estabilização brasileiros implantados no período em questão. Como o preço do IDU pode refletir a credibilidade inerente ao plano macroeconômico em vigência, pode-se derivar, através da Figura 3, as expectativas formadas pelos agentes econômicos quanto ao sucesso de cada plano.

O primeiro plano de estabilização do período em análise foi o Plano Cruzado. Este plano, implantado em fevereiro de 1986, tinha o congelamento de preços e salários como principal ferramenta para controlar a inflação. De acordo com o comportamento do preço do IDUs, o plano não teve expressiva credibilidade nos primeiros meses, perdendo-a nesse mesmo ano, quando o nível geral de preços voltou a subir.

À medida que a inflação ia aumentando, crescia a necessidade de um novo plano de estabilização. A nomeação do novo Ministro da Fazenda, Luís Carlos Bresser, e o projeto de um novo plano de estabilização elevaram um pouco as expectativas dos agentes econômicos, no período que antecedeu sua implementação. Contudo, como pode ser visualizado na Figura 3, a perda substancial de credibilidade deu-se logo após a implementação do plano, que também tinha o congelamento de preços e salários como principal instrumento de controle, com um pouco mais de flexibilidade que o plano anterior.

Os agentes econômicos já não se mostravam otimistas no período que antecedeu à implementação desse outro plano de estabilização - Plano Bresser - que continha as mesmas características do anterior - Plano Cruzado. Neste período, o preço do IDU caiu bruscamente no mercado secundário. O Plano Bresser consegue um pequeno ganho de credibilidade após sua implementação, mas a perde logo depois, quando a inflação volta a subir.

As expectativas formadas pelos agentes econômicos se mostraram favoráveis e otimistas quanto ao novo governo que assumiu efetivamente em março de 1990. Fernando Collor de Mello, novo Presidente da República, introduziu um surpreendente programa antiinflacionário. $O$ novo programa tinha como principal instrumento o congelamento de $80 \%$ de todos os depósitos do overnight, contas correntes ou de poupança que excedessem a NCz\$50 mil (equivalentes a US\$1.300 pelo câmbio da época), conforme enfatiza Baer (1996). A queda brusca de liquidez provocou uma diminuição significativa das atividades econômicas e foi 
acompanhada por um declínio da credibilidade do programa, evidenciado por um novo período de queda de preço do IDU no mercado secundário, mostrado na Figura 3.

Figura 3 - Proxy de Credibilidade e os Planos de Estabilização Brasileiros, jan/86 - mar/97.

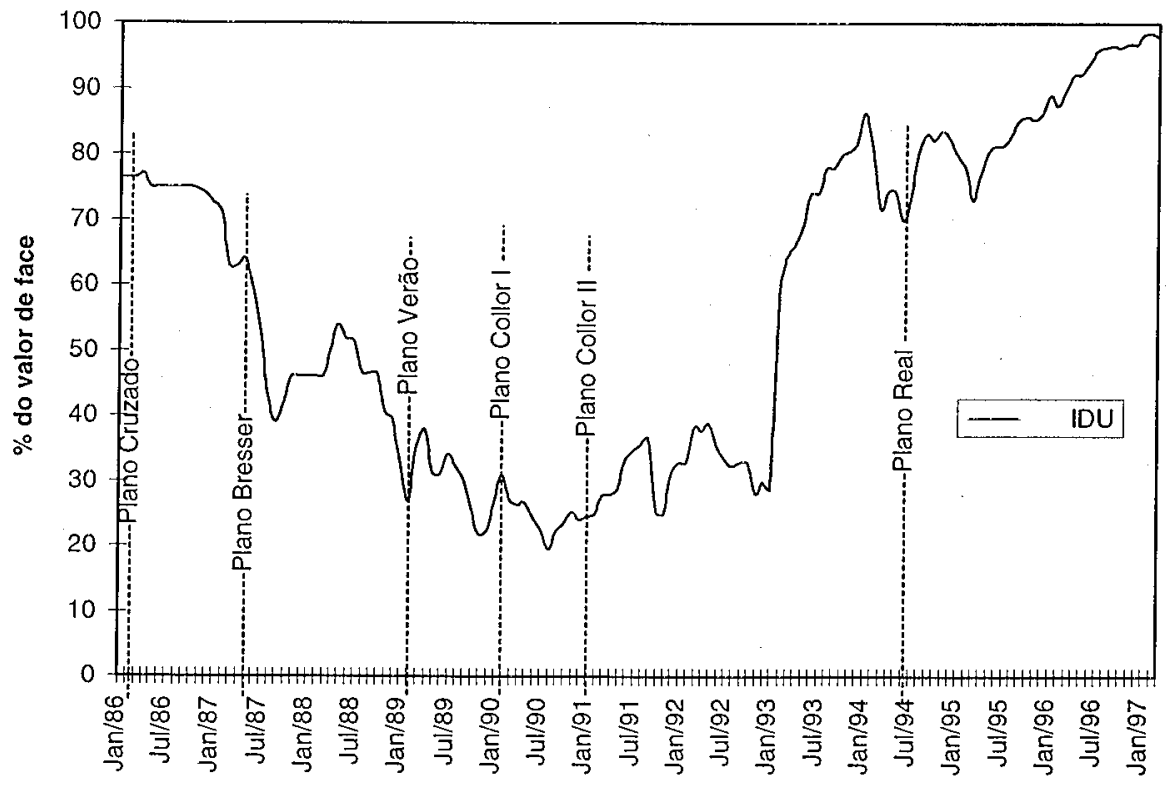

Inserido em um contexto de baixa credibilidade, o programa antiinflacionário que sucedeu ao Plano Collor I, chamado de Plano Collor II, implantado em janeiro de 1991, pouco contribuiu para a estabilização. Baseado no congelamento de preços e salários e na extinção de várias formas de indexação, o Plano Collor II começou a ganhar um pouco de credibilidade, mas depois a perdeu, assim como não conseguiu controlar a inflação.

A Figura 3 mostra uma brusca elevação do preço do IDU, no mercado secundário, a partir de janeiro de 1993. Como também existem outros fatores que afetam seu preço, essa elevação pode ser parcialmente entendida como parte de um programa de renegociação da dívida externa nos moldes do Plano Brady. De acordo com Cerqueira (1995), em 10 de janeiro de 1993 foi encaminhado, pelo Brasil, à comunidade financeira internacional, um documento que solicitava aos credores externos a participação ao referido programa de renegociação. Isto, sem dúvida, 
provocou uma expectativa positiva quanto ao pagamento das obrigações externas do país, elevando o preço do IDU para acima de $80 \%$ do seu valor de face. Como as forças de mercado parecem ter atuado com demasiado otimismo, o preço do IDU iniciou um pequeno movimento descendente posteriormente, atingindo um patamar condizente com a realidade conjuntural brasileira da época.

Em dezembro de 1993 foi proposto um outro programa de estabilização de preços, o Plano Real, que contava com um ajuste fiscal e um novo sistema de indexação que levaria a uma nova moeda, a qual seria vinculada ao dólar. O programa recebeu apoio dos agentes econômicos logo após seu anúncio, conforme mostra a Figura 3 , havendo uma valorização do IDU.

Quando o Plano Real foi efetivamente implementado, em julho de 1994, os agentes se mostraram cada vez mais confiantes, o que é ilustrado pela tendência ascendente do preço do IDU .

Após a implantação do Plano Real, tem-se, todavia, um comportamento atípico do preço do IDU. O preço começa a declinar em dezembro de 1994 e só se recupera em março de 1995. Contudo este movimento tem pouca relação com o andamento da política interna ou o sucesso do plano vigente. Foi, sobretudo, conseqüência da crise cambial mexicana, conhecida como "efeito tequila". De acordo com o International Monertary Fund (IMF) (1995), a crise mexicana provocou distúrbios em toda a América Latina. $O$ alto coeficiente de correlação existente entre os papéis da dívida externa latinoamericana, no período da crise, provocou o movimento de desvalorização em conjunto desses bônus. A Tabela 2 mostra o coeficiente de correlação entre os papéis da dívida externa de alguns países latino-americanos em dois intervalos de tempo. Essa situação deveu-se, principalmente, ao aumento explosivo dos spreads (prêmio de risco) cobrados pelos organismos financeiros internacionais, no período dez/94 - mar/95.

Tabela 2 - Correlação entre os Preços dos Papéis da Dívida Externa de Países Selecionados em 2 períodos, jan/93 - jan/94 e dez/94 - mar/95

\begin{tabular}{|l|c|c|}
\hline & Brasil - (jan/93 - jan/94) & Brasil - (dez/94 - mar/95) \\
\hline Argentina & 0,23 & 0,80 \\
México & 0,56 & 0,89 \\
Venezuela & 0,19 & 0,83 \\
\hline
\end{tabular}

Fonte: Estimativas do IMF (1995) baseadas em dados do Salomon Brothers.

Os spreads cobrados para o Brasil, Argentina, México, Venezuela, dentre outros, aumentaram de menos de 500 pontos antes da crise para mais de 2000 pontos, em média, em meados de fevereiro de 1995. A situação só voltou a se normalizar (e o preço do IDU se restabelecer) a partir de março de 1995. 
Afora esta situação exógena à condução e andamento da política interna, o Plano Real foi o programa de estabilização relativamente mais crivel do período analisado, como pode ser visto pela continua tendência de valorização do IDU.

\section{4 - CORRELAÇÃO ENTRE PREÇO DA DÍVIDA EXTERNA E TAXAS DE JUROS E RESERVAS}

Para testar se há uma associação positiva entre reservas internacionais e o IDU e um relacionamento inverso entre taxas de juros internacionais e internas com o título da dívida externa - hipótese de Dooley et alli (1996) -, faz-se uma análise de correlação do tipo:

$$
\tau=\operatorname{corr}\left(\text { IDU: } i^{\star}, i, R\right) \text {; }
$$

onde: $\tau=$ coeficiente de correlação entre IDU e os componentes $i^{*}$, i e $R$, tomados individualmente; $i^{*}=$ taxa de juros externa; $i=$ taxa de juros interna e; $R=$ nivel de reservas internacionais.

Todos os dados referentes a essa análise possuem periodicidade mensal e são correspondentes ao período jan/86 - mar/97. Utiliza-se a LIBOR como representativa das taxas de juros externas, porque a maioria dos empréstimos, e os próprios bônus de negociação, são baseados nesta taxa. Os dados referentes à LIBOR possuem maturação de seis meses e são anualizados. Para desanualizá-los, utiliza-se o método de juros compostos. A LIBOR foi coletada da Revista Conjuntura Econômica.

No caso das taxas de juros internas, foi utilizada a overnight, também coletada da Revista Conjuntura Econômica. Os dados referentes às reservas internacionais foram coletados do Boletim do Banco Central e seus valores são expressos em milhões de US\$.

Para se testar a hipótese de Dooley et alli (1996), conforme definido acima, fez-se uma análise de correlação entre o preço do IDU e a LIBOR. O passo inicial foi desanualizar a LIBOR. Posteriormente, procedeu-se a uma análise de correlação com dados mensais para o período jan/86 - mar/97. A Figura 4 ilustra o comportamento das variáveis e a Tabela 3 mostra o coeficiente de correlação encontrado.

O resultado indica que, no período em questão, houve uma correlação negativa entre as variáveis IDU e LIBOR na ordem de $41,08 \%$. O t calculado $(-5,1751)$ sinalizou a rejeição da hipótese de que não há existência de correlação a $1 \%$ de significância.

Percebe-se claramente na Figura 4 que estas variáveis realizam um movimento oposto uma da outra. Quando a taxa de juros externa está alta, o preço do IDU, no mercado secundário, cai drasticamente. Conforme enfatizado por Dooley et alli (1996), quando a taxa de juros internacional 
(LIBOR) aumenta, há uma expectativa negativa quanto ao pagamento do serviço da dívida, o que provoca uma queda no valor presente esperado do fluxo de pagamentos. Assim sendo, cai o preço do IDU negociado no mercado secundário.

Figura 4- Comportamento do IDU e da LIBOR, jan/86 - mar/97.

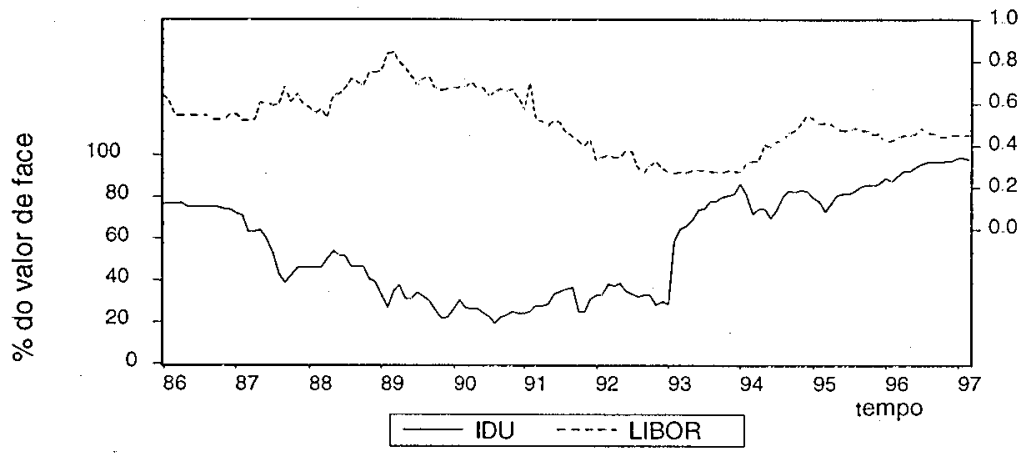

Tabela 3 - Matriz de Correlação entre

Preço do IDU e LIBOR, jan/86 - mar/97

\begin{tabular}{|c|c|c|}
\hline & IDU & LIBOR \\
\hline IDU & 1,000000 & $-0,410856$ \\
LIBOR & 0,410856 & 1,000000 \\
\hline
\end{tabular}

$\mathrm{Na}$ análise de correlação entre o IDU e o OVER, os resultados mostraram, conforme pode ser visto na Tabela 4, que há também entre eles uma correlação negativa. O teste para o coeficiente encontrado rejeitou a hipótese de que não há correlação entre o IDU e o OVER a $1 \%$ de significância, com o t calculado no valor de $-4,8453$.

Tabela 4 - Matriz de Correlação entre o IDU e o OVER, jan/86 - mar/97.

\begin{tabular}{|c|c|c|}
\hline & IDU & OVER \\
\hline IDU & 1.000000 & $-0,388592$ \\
OVER & $-0,388592$ & 1,000000 \\
\hline
\end{tabular}

Os resultados sugerem que uma taxa de juros interna muito elevada provoca uma diminuição do preço do IDU. A Figura 5 ilustra o movimento oposto destas variáveis para o período em questão. Enquanto a taxa de juros interna aumenta, o preço do IDU realiza um movimento decrescente no mercado secundário. 
Figura 5 - Comportamento do Preço do IDU e do OVER, jan/86 - mar/97.

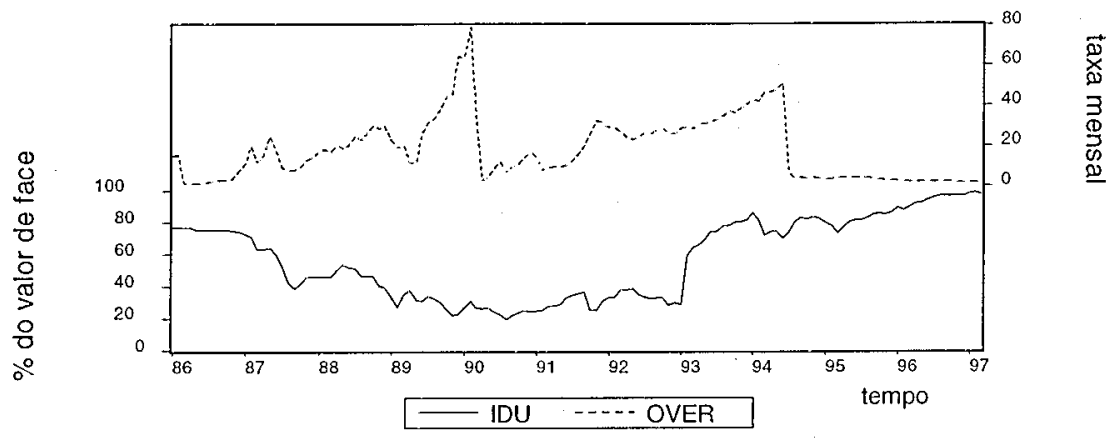

O comportamento oposto do IDU em relação ao OVER deve-se ao fato de que quando as taxas de juros internas estão muito altas, a rolagem da dívida pública interna se torna muito onerosa e, dada a limitação de recursos do governo, cria-se uma expectativa negativa quanto à possibilidade de pagamento do serviço da dívida externa.

Conforme esperado, na análise de correlação entre o preço do IDU e reservas internacionais, por outro lado, o coeficiente encontrado foi positivo, como pode ser visualizado na Tabela 5 . O teste para o coeficiente mostra que a correlação é significativa a $1 \%$ de significância, com o t calculado no valor de 13,0212 .

Tabela 5 - Matriz de Correlação entre o IDU e Reservas Internacionais, jan/86 - mar/97

\begin{tabular}{|c|c|c|}
\hline & IDU & Reservas \\
\hline IDU & 1,000000 & 0.750021 \\
Reservas & 0,750021 & 1,000000 \\
\hline
\end{tabular}

Este resultado também comprova a hipótese de Dooley et alli (1996) de que há uma correlação positiva entre o preço do IDU e o nível de divisas estrangeiras. A Figura 6 ilustra o comportamento dessas variáveis, mostrando que geralmente elas caminham no mesmo sentido.

Como os preços dos títulos da divida externa indicam aos investidores estrangeiros o risco inerente aos fluxos de capitais externos para o país devedor, quando o preço do IDU está alto, há um aumento dos fluxos de capitais para o Brasil e, consequentemente, uma elevação do nível de reservas internacionais. Isto explica, portanto, o alto coeficiente de correlação encontrado para estas variáveis. Por outro lado, o aumento das reservas internacionais eleva as expectativas dos investidores quanto ao pagamento das obrigações da dívida externa. 
Figura 6 - Comportamento do Preço do IDU e das Reservas Internacionais, jan/86 - mar/97

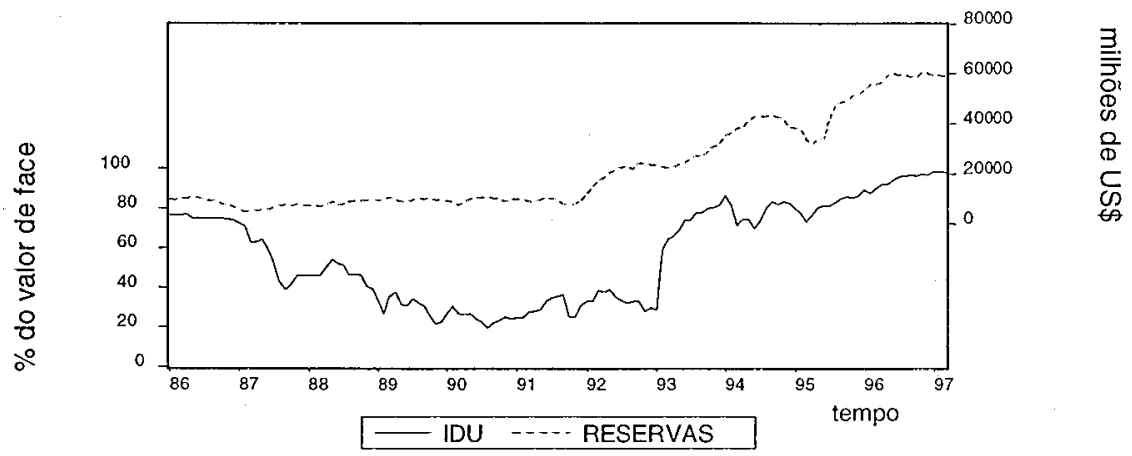

\section{5 - CONCLUSÕES}

A credibilidade de um programa de estabilização é de crucial importância para seu sucesso. O objetivo central deste trabalho foi construir uma proxy empírica de credibilidade das políticas macroeconômicas brasileiras, baseando-se nos títulos da dívida pública externa negociados no mercado secundário.

Desde a crise da dívida externa em 1982, os bancos credores iniciaram uma corrida para se livrarem de seus investimentos arriscados - dívida dos países em desenvolvimento - e passaram, então, a vender os títulos dessas dívidas no mercado secundário. Como os investidores no mercado secundário pagam por estes papéis um preço que reflete tanto a capacidade do país devedor de se ajustar internamente como o de honrar o serviço da dívida, testou-se, em primeiro lugar, se esses papéis podem ser utilizados como proxy empírica de credibilidade. Para isto, fez-se uma análise de correlação entre o título da dívida externa brasileira antiga (IDU) e inflação esperada, verificando, conforme esperado, uma associação negativa entre essas variáveis.

Após a identificação do IDU como possível proxy de credibilidade, fezse um breve confronto desta proxy com os programas de estabilização brasileiros implantados no período jan/86 - mar/97. Os resultados encontrados sugerem que, para o intervalo de tempo analisado, e em comparação com planos econômicos anteriores, o Plano Real foi o mais crível. O comportamento do IDU mostrou, para o Plano Real, uma expectativa positiva dos agentes econômicos quanto ao futuro da economia. 
Fez-se, posteriormente, uma análise de correlação entre os fatores que podem afetar o preço do IDU. Encontrou-se uma correlação negativa entre o IDU e as taxas de juros internas, o que consolida a hipótese de Dooley et alli (1996) de que uma elevada taxa de juros interna pode aumentar os dispêndios com a rolagem da dívida pública interna, criando uma expectativa negativa quanto à possibilidade do país honrar o serviço da dívida externa. No caso da taxa de juros externa, os resultados também sugerem que um aumento desta provoca uma diminuição do valor presente esperado do fluxo de pagamentos da dívida externa, o que faz com que o preço do IDU caia no mercado secundário. Encontrou-se, também, uma associação positiva entre o nível de divisas internacionais e o preço do IDU. Isto deve-se, principalmente, ao fato de que quando o nível de reservas internacionais está elevado, cria-se, no mercado secundário, uma expectativa positiva de que o país conseguirá honrar o serviço da dívida externa.

O fato de o IDU estar correlacionado com outras variáveis exógenas à condução da política econômica interna amplifica sua utilização como proxy de credibilidade. Em uma economia globalizada, o sucesso de um plano de estabilização ou de uma política econômica não depende somente do programa interno do policymaker, mas também do comportamento e das expectativas da economia mundial.

\section{BIBLIOGRAFIA}

ARBEX, M.A.; FONTES, R. e ALMEIDA, M. Inflação e Credibilidade: Uma Resenha. In:

FONTES, R. (Ed.). Estabilização e Crescimento, Viçosa: Editora UFV. p.13-54, 1997.

BACHA, E, L. O Fisco e as Divisas: Um Novo Enfoque para a Divida Externa. Nova Economia, Belo Horizonte: UFMG/FACE/DCE, v. 1, nº 1, p. 37-51, 1990.

BAER, W. A Economia Brasileira, São Paulo: Nobel. 1996.

BANCO CENTRAL DO BRASIL. Relatório, Brasilia, v. 31, 1994.

Boletim Do Banco Central Do Brasil. Brasília, v. 32, nº 7 ,

1996. Boletim Do Banco Central Do Brasil. Vários Volumes.

CAMARGO, J. M. Do Milagre à Crise: A Economia Brasileira nos Anos Oitenta. Dívida Externa, Recessão e Ajuste Estrutural - O Brasil Diante da Crise. Rio de Janeiro: Paz e Terra, p. 181-189, 1982.

CARMICHAEL J. The Debt Crisis: Where Do We Stand After Seven Years?. The World Bank Research Observer, vol. 4, ํㅡㄹ, p. 121-142, 1989.

CERQUEIRA, C. A. A Negociação dos Acordos da Divida de 1994. Boletim de Diplomacia Econômica. Brasília, Banco Central do Brasil, 1995.

COHEN, D. The Management of the Developing Countries' Debt: Guidelines and Applications to Brazil. The World Bank Economic Review, vol. 2, no 1, p. 77-103, 1988. 
Debt Relief: Implications of Secondary Market Discounts and Debt Overhangs. The World Bank Economic Review, vol. 4, n 1, p. 43-53, 1990.

CRUZ, P.R.D.C. Endividamento Externo e Transferência de Recursos Reais ao Exterior: Os Setores Público e Privado na Crise dos Anos Oitenta. Nova Economia. Belo Horizonte: UFMG/FACE/DCE, v. 5, no 1, p. 121-144, 1995.

- Dívida Externa e Política Econômica - A Experiência Brasileira nos Anos Setenta, Brasília: Brasiliense, 1984.

DOOLEY,M.; FENÁNDEZ-ARIAS, E.; e KLETZER, K. Is The Debt Crisis History? Recent Private Capital Inflows to Developing Coutries. The World Bank Economic Review, v. 10, $n^{\circ} 1$, p. 27-50, 1996.

DORNBUSCH, R. As Dívidas dos Países em Desenvolvimento. Revista de Economia Política. São Paulo: Brasiliense. v. 8, $n^{0}$ 1, p. 14-50, 1988.

EATON, J. Sovereign Debt: A Primer. The World Bank Economic Review, v. 7, n. 2, p 137-173, 1993.

FERRER, A. Dívida Externa, Estratégia de Desenvolvimento e Política. Revista de Economia Política, São Paulo: Brasiliense, v. 7, nº 2, p. 41-54, 1987.

FILHO, P. P. Plano Brady - da Retórica à Realidade. Estudo Econômicos. São Paulo: IPE/USP, v.24, n. 1, p. 54-105, 1994.

FUNDAÇÃO GETÚLIO VARGAS. Revista Conjuntura Econômica. Vários números.

HORTA, M. H. Renegociação da Dívida Externa. Perspectiva da Economia Brasileira 1992. Rio de Janeiro: IPEA, p. 81-105, 1991.

LOPES, F. A Crise do Endividamento Externo: Alguns Números e Suas Consequências. Divida Externa, Recessão e Ajuste Estrutural - O Brasil Diante da Crise, Rio de Janeiro: Paz e Terra, p. 95-107, 1982.

MOFFIT, M. O Dinheiro do Mundo - de Bretton Woods à Beira da Insolvência. Rio de Janeiro: Paz e Terra, 1984.

MOLLO, M. L. Instabilidade do Capitalismo, Incerteza e Papel das Autoridades Monetárias: Uma Leitura de Minsky. Revista de Economia Política. São Paulo: Brasiliense, v. 8, ํㅜ 1, p.100-123, 1988.

PERSSON, T. Credibility of Macroeconomic Policy: An Introduction and a Broad Survey. European Economic Review, 32, p. 519-532, 1988.

RESENDE, A.L. A Ruptura no Mercado Internacional de Crédito. Dívida Externa, Recessão e Ajuste Estrutural - O Brasil Diante da Crise, Rio de Janeiro: Paz e Terra, p. 41-55, 1982.

SACHS, J.D. e F. B. LARRAIN. Macroeconomia, São Paulo: Makron Books, p. 777-817, 1995.

SERRA, J. Conversão da Dívida. Revista de Economia Política. São Paulo: Brasiliense, v. 8, n. 1, p. 124-131, 1988. 